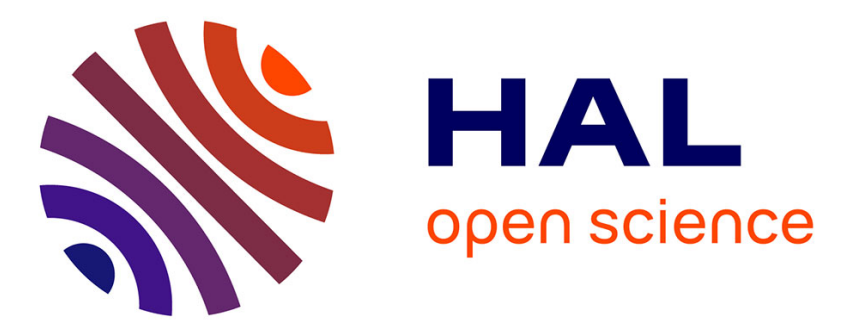

\title{
Guidelines for Designing Human-Friendly User Interfaces for Factory Floor Manufacturing Operators Eeva Järvenpää, Minna Lanz
}

\section{To cite this version:}

Eeva Järvenpää, Minna Lanz. Guidelines for Designing Human-Friendly User Interfaces for Factory Floor Manufacturing Operators. IFIP International Conference on Advances in Production Management Systems (APMS), Sep 2015, Tokyo, Japan. pp.531-538, 10.1007/978-3-319-22759-7_61 . hal-01431142

\section{HAL Id: hal-01431142 \\ https://hal.inria.fr/hal-01431142}

Submitted on 10 Jan 2017

HAL is a multi-disciplinary open access archive for the deposit and dissemination of scientific research documents, whether they are published or not. The documents may come from teaching and research institutions in France or abroad, or from public or private research centers.
L'archive ouverte pluridisciplinaire HAL, est destinée au dépôt et à la diffusion de documents scientifiques de niveau recherche, publiés ou non, émanant des établissements d'enseignement et de recherche français ou étrangers, des laboratoires publics ou privés. 


\title{
Guidelines for Designing Human-friendly User Interfaces for Factory Floor Manufacturing Operators
}

\author{
Eeva Järvenpää* and Minna Lanz \\ Tampere University of Technology, Department of Mechanical Engineering and Industrial \\ Systems, Tampere, Finland \\ \{eeva.jarvenpaa, minna.lanz\} @tut.fi
}

\begin{abstract}
Agility and fast reaction to changes is required in today's turbulent manufacturing environment. Unfortunately, the commonly used user interfaces (UIs) on the factory floor don't support such rapid reaction. Even though the human involvement improves agility and reactivity of production systems, it is also a source of uncertainty, especially when it comes to information inputting. Therefore, specific attention should be placed on human-friendly UI design, in order to improve the reliability of collected data and productivity of operations, as well as to make the workplaces more attractive for the future operators. This paper gives generic guidelines for human-friendly UI design and represents a case study in the context of manufacturing IT-system design.
\end{abstract}

Keywords: User-centric design, human-friendly design, user interfaces, manufacturing environment, manufacturing IT-systems

\section{Introduction}

Human factors play a crucial role in manufacturing. The desire towards more agile and responsive manufacturing requires that real time information of the production plan, status and other relevant aspects is always visible for those who need it, when they need it. This, in turn, requires that the information is, on one hand collected from the production processes, and on the other hand displayed to the workers in a humanfriendly way. Still common manual practices in information inputting, e.g. re-typing information from paper documents to IT-systems, don't allow real time transparency to the operations, neither provide reliable and timely information of the realized production.

The interviews conducted among 25 Finnish manufacturing companies [1] showed that even though the companies have not yet widely adopted proper manufacturing IT-solutions, such as Manufacturing Execution Systems (MES), there is a strong desire to increase the digitalization in manufacturing. MES would support real time data collection from the manufacturing operations in a digital format, and this data could be used throughout the organization for better and more synchronized management and control of the operations [2]. In order to mitigate problems relating to human perceptual and cognitive capabilities, as well as behaviour, a special attention should

adfa, p. 1, 2011.

(C) Springer-Verlag Berlin Heidelberg 2011 
be paid on the design and selection of good and intuitive user interfaces (UIs) for the new manufacturing IT-systems. The novel ways of working on the factory floor should not only improve the efficiency and quality of operations, but also be pleasurable for the workers. To attract future operators, the manufacturing sector should target to social sustainability and adopt new UI technologies in order to be more appealing and accessible for youngsters who have grown into a digital world [3].

This paper discusses a study conducted in an ongoing LeanMES-project. The project's objective is to create a lean, scalable and extendable concept for a new type of MES that supports human operator in a dynamically changing environment. One target is to study novel approaches for intuitive user interfaces. The purpose of this paper is to draw the background for the development of UIs for factory floor operators by highlighting some relevant theory for user-centric design, and identifying and analysing the current challenges and needs of manufacturing companies. The focus of this paper is on information display and collection.

\section{Research method}

The characteristics of a good design depends on the users, tasks and context of use of the designed technology (e.g. [4][6]). Therefore the research approach taken for this study was to analyse all these three aspects, namely users, tasks and context. The research, discussed in this paper, consists of the following steps:

1. Interviews: The data for the analysis was collected form the interviews conducted among 25 Finnish manufacturing companies mainly from machine building industry. In each company three types of personnel were interviewed to get a comprehensive view on the needs, current challenges and underlying context: 1) plant or production manager; 2) production worker and 3) main user of the production planning and execution system or IT manager. The questions focused on the everyday production planning and control, change situations, data collection and search, quality control practices and work instructions. For more information on the interviews, please refer to [1].

2. Literature review: Literature review on user-centric design, human-computer interaction, and existing and emerging UI technologies was conducted. The purpose was be able to take into account the relevant characteristics when making selections for proper input and output modalities, medias, technologies and display designs.

3. Task analysis: As LeanMES-project focuses on the information flows and visibility, the main focus in the task analysis was to map the required information inputs and outputs on different workstations and tasks. The purpose was not to perform this analysis for any individual company, but to generalize the results for machine building industry.

4. Analysis of suitable input and output modalities, media and UI technologies: While designing user interfaces, three selections need to be made: 1) Selection of the modality, which refers to the sensory channel that human uses to send and receive a message (e.g. auditory, visual, touch); 2) Selection of the medium, which 
refers to how the message is conveyed to the human (e.g. diagram, video, alarm sound); and 3) Selection of the technology to deliver the message (e.g. smart phone or workshop PC). These were analysed on the basis of the task requirements.

\section{User-centric, human-friendly user interface design}

\subsection{Human characteristics relevant for usable design}

Based on [4], whether a system can be described being usable or not depends on four factors, namely anthropometrics, behaviour, cognition and social factors. Anthropometrics refers to the physical characteristics, such as body type and size, of the intended users. Behaviour refers to the perceptual and motivational characteristics of users, looking at what people can perceive and why they do what they do. Behavioural characteristics are mostly related to the sensation with the basic senses (sight, hearing, touch, smell and taste) and interpretation of the sensed stimuli. Cognitive factors include learning, attention and memory and other aspects of cognition that influence on how users think and what they know and what knowledge they can acquire. Social factors consider how groups of users behave, and how to support them through design. [4]

Attention refers to the selective aspects of perception, which function so that at any instant a user dedicates his limited information processing capacity to the purposeful manipulation of a subset of available information [7]. According to [8] many studies have shown that it is easier to perform two tasks together when they use different stimulus or response modalities, than when they use the same modalities. According to multiple resource models, different attentional resources exist for different sensorymotor modalities and coding domains [8].

Mental models are used to understand systems and to interact with systems. Based on Ritter et al. [4] mental model can be considered as a representation of some part of the world that can include the structures of the world, how they interact and how the user can interact with them. Payne [9] simplified the meaning of mental models into "what users know and believe about the systems they use". The model the user brings to the task will influence how they use the system, what strategies they will most likely employ, and what errors they are likely to make. It is therefore important to design the system in such a way that the user can develop an accurate mental model of it. [4] One important concept, which aids in building the correct mental model of the system, and therefore easing its usage, is the stimulus-response (S-R) compatibility. This means that there should be clear and appropriate mappings between the task/action and the response. It is typically seen as having physical aspects of an interface (e.g. buttons) and displays match the world that they are representing. [7]

\subsection{Guidelines for designing interfaces with good usability}

Several authors have given guidelines and heuristic principles for designing user interfaces with good usability. In the following are collected the most relevant guidelines specifically for LeanMES-project's purposes. 
- Usage of terms and language: The system should speak the user's language and use words they already know and which are relevant for their context. The UI should exhibit consistency and standards so that the same terms always mean the same thing. Consistent use of words strengthens the chances of later successfully retrieving these words from the memory. [4],[10]

- Use recognition rather than recall: Systems that allow users to recognize actions they want to do will be easier initially to use than those that require users to recall a command. [4],[10]

- Favour words over icons: Instead of displaying icons, words may be better. This is because retrieving names from memory is faster than naming objects. [10]

- Information reliability and quality: The user should not be provided with false, misleading, or incomplete information at any time [11].

- Show only information which is needed: The system should be aesthetic and follow minimalist design, i.e. do not clutter up the UI with irrelevant information [10].

- Provide feedback for the user: The current system status should always be readily visible to the user [4],[10],[11].

- Make available actions visible: Make the actions the user can (and should) perform easier to see and to do [4].

- Allow flexibility for different users: The system should have flexibility and efficiency of use across a range of users, e.g. through keyboard short-cuts for advanced users. [10]

- Ensure that critical system conditions are recoverable: The user should have the control and freedom to undo and redo functions that they mistakenly perform [10], [11].

In their book Wickens et al. [12] defined 13 principles for display design, which should be taken into account when designing the LeanMES UIs:

- Perceptual principles: 1) Make displays legible (or audible); 2) Avoid absolute judgement limits; 3) Remember that user's past experience affects to how the signals are likely to be perceived and interpreted; 4) Build redundancy to the system, i.e. present the same signal in multiple different forms or modalities; 5) Use discriminable elements.

- Mental model principles: 6) Utilize pictorial realism, i.e. make a display to look like the variable that it represents; 7) Put the moving elements to move in a pattern and direction compatible with the user's mental model.

- Principles based on attention: 8) Minimize information access cost by allowing for frequently accessed sources to be located at the nearest possible position; 9) If divided attention between two information sources is necessary for the completion of one task, make them to have close mental proximity; 10) Utilize different cognitive resources (e.g. vision and hearing) if multiple information must be presented simultaneously.

- Memory principles: 11) Replace memory with visual information; 12) Provide information predictively; 13) Utilize consistency among different displays. 
Several things have to be considered when designing visual communications, such as web pages, different visual displays or dashboards. These include aspects such as typography (including typeface, its style, size, word spacing, leading, line length), colour, field of vision, page layout design, and amount of information on display. When using colour to show e.g. qualitative differences or highlight key data, it should be remembered that at least $9 \%$ of population is colour-deficient. Thus, colour should not be used as an only cue. [13] Often the display size is limited, especially with hand-held devices. When evaluating how much information should be presented on the display screen, the demands from cognitive and visual perspectives may be contradicting. According to [14], presenting little information on a screen at time helps to avoid visibility problems resulting from high-information density. On the other hand, presenting as much information on screen as possible allows users to have maximum foresight (cognitive preview) of other functions on the menu, which should benefit information access from a cognitive point of view and minimize disorientation. [14]

\section{$4 \quad$ Results}

\subsection{Identified challenges relating to information inputting and display}

The performed interviews revealed multiple challenges relating to the current information inputting and display practices on the factory floors. The main challenges, encountered especially in small and medium sized companies, are summarized below:

1. The paper work orders and documents, still commonly used to control the production and to collect information from the factory floor (e.g. time stamps, quality data, measurements), were regarded as problematic, because they don't provide real time information of the operations and their status. In addition, the information written on paper must be re-typed to IT-systems, which is non-value adding manual work, prone to human errors.

2. Paper documents are cumbersome to update and they get easily lost, e.g. work instructions are not up-to-date and rescheduling or re-routing of the orders requires the production supervisor to go physically to each workstation to change the order of the jobs.

3. The current information inputting practices don't produce reliable, timely data of realized production. Many companies stated that the operators tend to forget to record the receipts or they do it only once a day. The existing UIs are cumbersome to use, or are not in the same physical location with the operator (e.g. shared computers). This has often led to such practice that the recordings are done in batches rather than immediately after the event that should be recorded.

4. The recordings or information search require often long sequence of numbers, e.g. serial, order or project number, to be manually typed to the system. This is time consuming and error prone activity.

5. The usability of the current IT-systems used in manufacturing is often poor. The operators may use substantial time of their day to searching for information. 


\subsection{Task analysis}

As LeanMES-project focuses on the information flows and visibility, not in humanmachine collaboration in general, the main focus in the task analysis was to map the required information inputs and outputs of different roles in the factory. The roles were defined based on the tasks which are performed on different workstations. The following tasks/workstations were analysed: machining (milling and turning), sheet metal cutting, welding, assembly, as well as material receiving and shipping. The generic information needs and outputs on different tasks/workstations were systematically identified based on the interviews and workshops with industrial partners, and drawn as information input-output graphs (Figure 1). These graphs didn't take a stand on if human involvement is needed or if machine can manipulate or produce the information automatically. The purpose was to allow different automation strategies and the allocation of the functions to either human or machine for example based on the Fitt's list (MABA-MABA approach) [4].

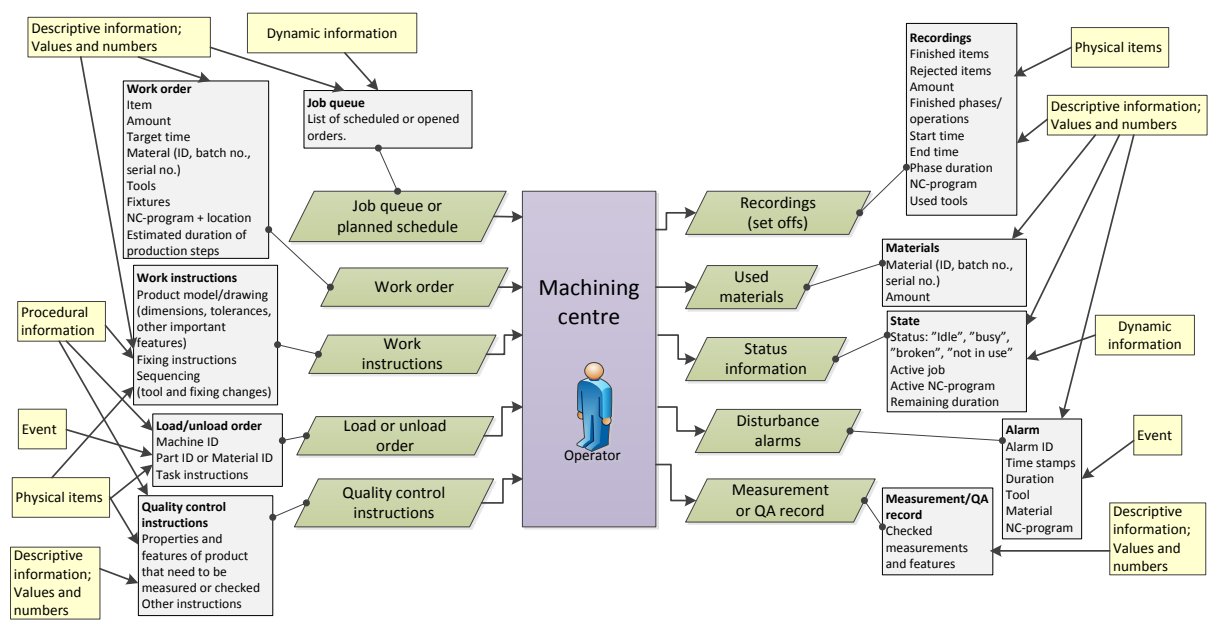

Fig. 1. Example of the information input-output graphs.

\subsection{Example of selecting the modality, media and technology}

The information elements in the input-output graphs were systematically categorized into physical items, spatial items, conceptual information, dynamic procedural information, events, descriptive information, values and causation, as exemplified in Figure 1. Based on this division, suitable modality and media were suggested for each information element relying on the heuristics presented by [15]. Below one example is discussed.

In case of the machining centre's loading or unloading order, the attention of the operator has to first be captured. Especially in multi-machine operating mode, when the operator is performing multiple tasks simultaneously and doesn't have direct visual sight to the machines all the time, the suitable modality for capturing the attention 
could be auditory or touch (haptic). This way the operator can concentrate on the current task at hand, which most probably requires visual attention, and simultaneously receive information about the upcoming task by using other attentional resources than vision. Such output could be produced e.g. by smartphone in the operator's pocket or smart watch in his/her wrist alerting, vibrating and possibly giving spoken information about the upcoming task. After capturing the operator's attention and guiding him/her to the correct machine, the task procedure has to be instructed to him/her. For such information, containing a lot of details and information elements, vision should be used as a main sensory channel. As discussed in [9], multi-media work instructions have been proved more powerful compared to single media instructions. Therefore, the detailed task procedure may be shown as a sequence of still images, video or animation, supplemented with text-based or audio instructions. For displaying this information, larger screen is preferred next to the machine, as not so much information can be conveyed through small smart phone display without compromising the visibility. When the task is completed, the operator should record the task done through the same UI by just one click. The task status gets updated to the MES and the information is immediately visible to others.

\section{$5 \quad$ Discussion and Conclusions}

Human-friendly UI design is crucial when aiming for efficient operations. The identified challenges in Finnish manufacturing companies clearly show that there is a need for digitalization and adoption of new UIs on the factory floors. As noticed during the interviews, human involvement increases flexibility of the production system, but also causes uncertainty to the information management processes. In order to mitigate this problem, a special attention should be placed on good and intuitive UIs and human-computer interaction technologies. These UIs should bring the needed information to the operator without searching and allow effortless information inputting. This paper highlighted some important human characteristics and design considerations for user-centric UI design, especially from the manufacturing IT-systems' perspective.

The goal of the LeanMES-project is to support human operator especially from the information acquisition and inputting viewpoints. Therefore the task analysis presented in this paper concentrated on identifying the needed information elements, rather than identifying the detailed steps (or their sequence) that the worker needs to perform in order to achieve their manufacturing related goals. Example of the selection of the suitable modalities, media and UI technologies for the identified information elements was shortly presented. The future work will include testing and analysing the suggested media and technologies in real industrial contexts.

\section{Acknowledgements}

This research was carried out as part of the Finnish Metals and Engineering Competence Cluster (FIMECC)'s MANU program in LeanMES-project. 


\section{References}

1. Järvenpää, E., Lanz, M., Tokola, H., Salonen, T. Koho, M.: Production planning and control in Finnish manufacturing companies - Current state and challenges. In: Proceedings of the 25th International Conference on Flexible Automation and Intelligent Manufacturing, FAIM2015, 23rd - 26th June, 2015, Wolverhampton, UK (2015)

2. J. Kletti (Ed.): Manufacturing Execution Systems - MES. 272 p. Springer (2007)

3. Berlin, C., Dedering, C. Jónsdóttir, G.R. \& Stahre. J.: Social Sustainability Challenges for European Manufacturing Industry: Attract, Recruit and Sustain. In: Proceedings of the Advances in Production Management Systems conference (APMS), Penn State, PA, USA, September 2013, Vol. 414, p. 78-85 (2013).

4. Ritter, F.E., Baxter, G.D. \& Churchill, E.F.: Foundations for designing user-centered systems - What System Designers need to know about people. 442 p. Springer. (2014)

5. Smith, P.J., Beatty, R., Hayes, C.C., Larson, A., Geddes, N.D. \& Dorneich, M.C.: HumanCentered Design of Decision-Support Systems. In: Jacko, J.A. (Ed.). The HumanComputer Interaction Handbook - Fundamentals, Evolving Technologies and Emerging Applications, 3rd Edition, pp. 589-621. CRC Press (2012)

6. Courage, C., Jain, J. Redish, J. \& Wixon, D.: Task Analysis. In: Jacko, J.A. (Ed.). The Human-Computer Interaction Handbook - Fundamentals, Evolving Technologies and Emerging Applications, 3rd Edition, pp. 956-982. CRC Press (2012)

7. Welsh, T.N., Chandrasekharan, S., Ray, M., Neyedli, H., Chua, R. \& Weeks, D.J.: Perceptual-Motor Interaction - Some Implications for Human-Computer Interaction. In: Jacko, J.A. (Ed.). The Human-Computer Interaction Handbook - Fundamentals, Evolving Technologies and Emerging Applications, 3rd Edition, pp. 3-20. CRC Press (2012)

8. Proctor, R.W. \& Vu, K-P.I.: Human Information Processing - An Overview for HumanComputer Interaction. In: Jacko, J.A. (Ed.). The Human-Computer Interaction Handbook Fundamentals, Evolving Technologies and Emerging Applications, 3rd Edition, pp. 21-40. CRC Press (2012)

9. Payne, S.J.: Mental Models in Human-Computer Interaction. In: Jacko, J.A. (Ed.). The Human-Computer Interaction Handbook - Fundamentals, Evolving Technologies and Emerging Applications, 3rd Edition, pp. 41-55. CRC Press (2012)

10. Nielsen J.: 10 Usability Heuristics for User Interface Design. Web article. (1995) [Available in: http://www.nngroup.com/articles/ten-usability-heuristics/] [Accessed: 2.3.2015]

11. Hedge, A.: 10 principles to avoid XP-asperation. Ergonomics in Design, 11(3), pp. 4-9. (2003)

12. Wickens, C.D., Lee, J.D., Liu, Y. \& Gordon Becker, S.E.: An Introduction to Human Factors Engineering. Second ed. Upper Saddle River, NJ: Pearson Prentice Hall (2004)

13. Watzman, S. \& Re, M.: Visual Design Principles for Usable Interfaces - Everything is Designed: Why We Should Think before Doing. In: Jacko, J.A. (Ed.). The Human-Computer Interaction Handbook - Fundamentals, Evolving Technologies and Emerging Applications, 3rd Edition, pp. 315-340. CRC Press (2012)

14. Schlick, C.M., Winkelholz, C., Ziefle, M. \& Mertens, A.: Visual Displays. In: Jacko, J.A. (Ed.). The Human-Computer Interaction Handbook - Fundamentals, Evolving Technologies and Emerging Applications, 3rd Edition, pp. 157.-191. CRC Press (2012)

15. Sutcliffe, A.: Multimedia User Interface Design. In: Jacko, J.A. (Ed.). The HumanComputer Interaction Handbook - Fundamentals, Evolving Technologies and Emerging Applications, 3rd Edition, pp. 387-404. CRC Press (2012) 